\title{
Los tres ojos del cíclope
}

\author{
The three eyes of the Cyclops
}

\author{
Sandra Jubelly García (Colombia) \\ Institución Universitaria Politécnico Grancolombiano \\ sandrajubelly@gmail.com \\ Máster en Escrituras Creativas
}

\section{Resumen}

El presente artículo surge de una investigación en la que se propuso precisar el vínculo entre la Violencia y el cine colombiano y el modo en que este expresa la violencia. En un primer momento se delimitó el periodo por estudiar, que para la cinematografía colombiana fue de 1990 a 2008, y para la historia de Colombia el que abarcó desde el Frente Nacional hasta 2008, periodo al que se denomina "tercera Violencia". En primera instancia se vieron los hechos violentos que caracterizaron el periodo histórico en mención, para luego, a partir de un análisis comparativo, observar de qué manera el cine colombiano incorporó esa

\section{Abstract}

This article arises from an investigation in which it was proposed to clarify the link between violence and the Colombian film making and how this expresses the violence. Initially, the study period was delimited, according to Colombian film making it was from 1990 to 2008, and for Colombian history the period from Frente Nacional until 2008, a period which is called the "third violence." At first the violent acts that characterized the historical period in question were reviewed, then, from a comparative analysis, it was observed how the Colombian film making incorporated violence to its narrative. But other analysis were needed as research progressed,

\begin{tabular}{|c|c|c|}
\hline $\begin{array}{l}\text { FECHA DE RECEPCIÓN: } \\
\text { FECHA DE REVISIÓN: } \\
\text { APROBACIÓN: }\end{array}$ & $\begin{array}{r}12 \text { de junio de } 2013 \\
18 \text { de junio de } 2013 \\
22 \text { de julio de } 2013\end{array}$ & $\begin{array}{l}\text { Para CITAR ESte ARTículo / to CITE this ARticle } \\
\text { García, S. (2013). Los tres ojos del cíclope. Po- } \\
\text { liantea, (IX), 17, pp. 173-198. }\end{array}$ \\
\hline
\end{tabular}


violencia en su relato. Pero aun fueron necesarios otros análisis a medida que avanzaba la investigación, por ejemplo, cómo se configuran los imaginarios, de qué modo funcionan sobre la alteridad y cómo circula la ideología cuando el vehículo es el cine. De modo que este artículo intentará reproducir el periplo de la investigación y algunas reflexiones sobre el acto creativo.

Palabras clave: violencia, historia, cine, imaginarios. for example, how the imaginaries are configured, how they work on the otherness and how ideology circulates when the vehicle is cinema. So this article will attempt to emulate the research journey and some reflections on the creative act.

Keywords: violence, history, cinema, imaginaries. 


\title{
Los tres ojos del cíclope
}

\author{
The three eyes of the Cyclops
}

\author{
Sandra Jubelly García (Colombia) \\ Institución Universitaria Politécnico Grancolombiano \\ sandrajubelly@gmail.com \\ Máster en Escrituras Creativas
}

\section{Violencia}

Por supuesto que el término "violencia" apela a múltiples modos de ella: la violencia simbólica, la violencia de género, la violencia política, en fin, lo claro es que la violencia tiene múltiples formas que responden a dinámicas distintas en su ejercicio, pero la que nos atañe, de la que nos ocuparemos, es aquella que en el caso colombiano deviene de las tensiones políticas, que ha marcado nuestra historia durante años y que en su dinámica ha generado fenómenos como el desplazamiento forzado, los cordones de miseria, las desapariciones, las masacres y todo tipo de vulneración a los derechos humanos.

En virtud de lo cual nos hemos acogido al abordaje teórico que hace Walter Benjamin en su texto Para una crítica de la violencia.

En principio hay que observar que en este ensayo Walter Benjamin señala la proliferación de concepciones de la violencia en las que se la legitima jurídicamente a causa de su finalidad, es decir, cuando el fin justifica los medios y, en esa medida, la justificación de la violencia como medio si los fines son justos.

Esta popular concepción, según Benjamin, es estimulada por la biología darwinista, que "considera en forma del todo dogmática, junto con la selección natural, solo a la violencia como medio originario y único adecuado 
a todos los fines vitales de la naturaleza" (1991, p. 24), lo cual no permite juzgar la violencia en cuanto estaría justificada por los fines siempre que estos fueran justos.

En oposición a ello, Benjamin propone examinar la violencia no en relación con los fines que ella persigue, sino la violencia en sí misma.

En un plano ideal, no son los fines justos los que deben justificar los medios, sino la legitimidad de los medios los que garanticen la justicia de los fines o, en palabras de Benjamin, "el derecho positivo, por su parte, establece juicios sobre todo derecho en vías de constitución, únicamente a través de la crítica de sus medios. Si la justicia es el criterio de los fines, la legitimidad lo es el de los medios" (1991, p. 24).

Pero en el ensayo Benjamin va más allá del derecho positivo, y plantea la violencia en un plano histórico, según el cual esta es fundadora de derecho y, a la vez, conservadora de este (p. 30). De este modo, se explican los grandes cambios que, por ejemplo, dieron lugar a las transformaciones jurídicas en Occidente, que por medio de la violencia establecieron nuevos órdenes y sistemas de derecho y que, a su vez, los sostuvieron por la fuerza.
Pero, finalmente, lo que más nos interesa de la postura de Benjamin es la posibilidad de pensar que la violencia no es un sine qua non, es decir, la violencia no es una condición necesaria que no pueda ser pensada, reflexionada, en lo que se advierte que de ser pensada exista la posibilidad de que sea prescindible.

\section{Historia}

La historia no es un hecho juzgado, es más bien una construcción, una construcción que realiza el presente acerca del pasado, y aquí caben las palabras de Walter Benjamin: "La historia es objeto de una construcción cuyo lugar no está constituido por el tiempo homogéneo y vacío, sino por un tiempo pleno, "tiempoahora" (1971, p. 86).

Y como toda construcción, la historia tendrá un sesgo cognitivo, atribuido por quien la edifica. Por tal razón, no es posible una historia total y menos objetiva por más esfuerzos que hagan los historiadores. Esto no significa, en modo alguno, que el esfuerzo no haya que hacerse, por el contrario, esto pone de manifiesto que es necesario aguzar la vista y revisar con lupa la historia, las versiones de la historia que nos llegan a las manos. Porque, entre otras 
cosas, la historia ha sido hecha por los vencedores y, como ya lo señalaba Benjamin, "ni siquiera los muertos estarán a salvo del enemigo, si este vence. Y este enemigo no ha dejado de vencer" (p. 80).

Efectivamente, la historia la han hecho los vencedores, porque los vencidos, generalmente, son aniquilados o esclavizados; pero, en cualquier caso, silenciados. Basta con ver, por ejemplo, las Crónicas de Indias, que narraban los acontecimientos ocurridos durante la conquista de América, para notar la imposibilidad de la existencia de una historia desde el vencido o por el vencido, por cuanto un efecto frecuente y colateral en las prácticas de conquista es lo que podría llamarse sustracción de materia, siendo esta el conquistado:

Aquí es donde dice Francisco López de Gomára que salió Francisco de Morla en un caballo rucio picado, antes que llegase Cortés con los de a caballo, y que eran los santos apóstoles señor Santiago o señor San Pedro. Digo que todas nuestras obras y victorias son por mano de Nuestro Señor Jesucristo, y que en aquella batalla había para cada uno de nosotros tantos indios que a puñados de tierra nos cegaran, salvo que la gran misericordia de Nuestro Señor en todo nos ayudaba...
[...]

En este día, a la tarde, vimos un milagro bien grande, y fue que apareció una estrella encima de la nave después de puesto el sol, y se partió despidiendo rayos de luz a la continua, hasta que se usó sobre aquella villa o pueblo grande, y dejó un rastro en el aire que duró más de tres horas largas; y también vimos otras señales bien claras, por donde entendimos que Dios quería que poblásemos aquella tierra para su servicio... (Juan Díaz, Itinerario de la armada).

$[\ldots]$

En esa sazón vino una pestilencia de sarampión, y víroles tan recia y tan cruel, que creo murió más de la cuarta parte de la gente de indios que había en toda la tierra, la cual muy mucho nos ayudó para hacer la guerra y fue causa que mucho más presto se acabase, porque, como he dicho, en esta pestilencia, murió gran cantidad de hombres y gente de guerra y muchos señores y capitanes y valientes hombres, con los cuales habíamos de pelear y tenerlos por enemigos; y milagrosamente Nuestro Señor los mató y nos los quitó delante... (Bernardino Vázquez de Tapia, Relación de méritos y servicios, citado en Díaz del Castillo, 1939). 


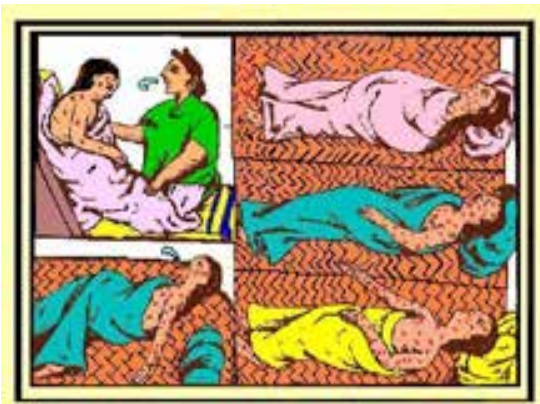

(Códice florentino, Epidemia de viruela).

\section{[...]}

Claro es que a los indígenas no solo los mató la espada del conquistador, sino la viruela, la sífilis y los piojos, plagas y enfermedades para las que no tenían defensas. Curiosa ironía que se habría de imaginar el conquistador, que además del frío acero contaría con las armas biológicas.

Pasaron siglos para que se revisara la historia y se reconociera que la conquista de América había sido un etnocidio, el exterminio y la aniquilación de una población en evidente desventaja.

Si no se revisa la historia, si no se le da la voz a quien no la tiene, el vencedor seguirá venciendo. En esta postura se entiende que Benjamin no solo toma partido por los vencidos, sino que de plano conjura toda pretensión de objetividad de la historia; para Benjamin la historia es un asunto de empatía y sostiene que generalmente la construcción de la historia ha establecido empatía con el poder y el poder está en el vencedor.

Para Benjamin hay dos tipos de historiadores: el historiador historicista y el materialista histórico. El primero entra en empatía con el vencedor, el segundo (el materialista histórico), ha sido llamado para reivindicar al vencido obedeciendo a un principio de equilibrio y de justicia, o en palabras de Benjamin: “C Con quién entra en empatía el historiador historicista? La respuesta es [tan] innegable que reza así: con el vencedor. Los respectivos dominadores son los herederos de todos los que han vencido una vez" (p. 81).

En estas palabras establece el deber del otro historiador, el que se ocupa de los vencidos, el que Benjamin llama materialista histórico:

Quien hasta el día actual se haya llevado la victoria, marcha en el cortejo triunfal en el que los dominadores de hoy pasan sobre los que también hoy yacen en tierra. Como suele ser costumbre, en el cortejo triunfal llevan consigo el botín. Se le designa como bienes de cultura. En el materialista histórico tienen que contar con un espectador distanciado. Ya que los bienes culturales que abarca con la mirada, tienen todos y cada uno un origen que no podrá considerar 
sin horror. Deben su existencia no solo al esfuerzo de los grandes genios que los han creado, sino también a la servidumbre anónima de sus contemporáneos. Jamás se da un documento de cultura sin que lo sea a la vez de la barbarie. E igual que él mismo no está libre de barbarie, tampoco lo está el proceso de transmisión en el que pasa de uno a otro. Por eso el materialista histórico se distancia de él en la medida de lo posible. Considera cometido suyo pasarle a la historia el cepillo a contrapelo (p. 81).

\section{Imaginarios}

Castoriadis (1988, p. 68) los refiere como un magma de significación que produce una relación simbiótica, pero, también de tensión entre lo instituido y lo instituyente.

El proceso de construcción de imaginarios es sumamente complejo y no es en modo alguno una imposición unilateral del poder, ni tampoco se generan exclusivamente por condiciones materiales o económicas. Para Castoriadis, si bien estas desempeñan un papel importante no son determinantes o constitutivas de los imaginarios.

En su conformación pesa en gran medida lo que se podría llamar potencia creativa de las sociedades. De modo que el imaginario social tiene tres niveles: 1) creativo instituyente; 2) legitimador que da lugar a las instituciones, y 3) el del disenso o la resistencia que garantiza un potencial cambio social o de statu quo. Pero no se debe entender en el orden planteado el proceso de producción de imaginarios, pues los imaginarios sociales, toda vez que crean e instituyen un orden social, son a la vez creados e instituidos por ese mismo orden, generando a un tiempo simbiosis y tensión entre lo instituido y lo instituyente.

Es cierto que una vez instituidos los imaginarios, estos dan lugar a las instituciones y estas mantendrán y justificarán un orden social y harán circular la ideología, que mostrará, pero también ocultará, una realidad social, de modo que todo aparato ideológico instituido hará visibles y privilegiará unos regímenes de verdad consensuados y ocultará otros que generalmente son minoritarios.

De modo que lo que en un momento originario funciona como la institución al servicio de la sociedad se convierte, luego de instituirse y legitimarse, en la sociedad al servicio de la institución.

A pesar de que, como hemos dicho, los imaginarios y en consecuencia la ideología responde a un 
consenso y circula legitimado por una mayoría social, existe un intersticio por el que se filtra el disenso, la resistencia, la autonomía, o la alteridad; a propósito de la autonomía Castoriadis hace la siguiente invitación: "deriva el imperativo práctico, deviene autónomo... y contribuye en todo lo que puedas al devenir autónomo de los demás" (1990, p. 78).

De modo que por instalado que esté un aparato ideológico siempre estará potencialmente amenazado, amenaza a la que generalmente las instituciones responden con violencia. Para entender un poco mejor esto quiero centrarme en la alteridad, en lo otro, en lo diferente que pone en crisis el orden instaurado en la norma, en otras palabras, en lo anormal.

\section{La alteridad y el orden}

Michel Foucault en el prefacio de Las palabras y las cosas (1968, p. 1) nos refiere un texto de Borges según el cual en cierta enciclopedia china los animales se clasifican en: 1) pertenecientes al emperador, 2) embalsamados, 3) amaestrados, 4) lechones, 5) sirenas, 6) fabulosos, 7) perros sueltos, 8) incluidos en esta clasificación, 9) que se agitan como locos, 10) innumerables, 11) dibujados con un pincel finísimo de pelo de camello, 12) etcétera, 13) que acaban de romper el jarrón, 14) que de lejos parecen moscas.

Esta extraña clasificación, además de producir risa, genera un cierto malestar y es a este malestar al que quiero referirme. El malestar que entraña el desorden. Todo aquello que se sale de la norma, amenaza el orden mismo, amenaza el estado de cosas e incomoda a quienes lo habitan cómodamente.

El hombre ha intentado dominar la naturaleza y para lograrlo ha tenido que entenderla, para lo cual ha ideado toda suerte de clasificaciones, de órdenes que le permitan el control, el control de sí mismo y de todo cuanto le rodea. Así, en todas las culturas se establecen órdenes políticos, sociales, morales, etcétera. Órdenes que cambian según los tiempos y en respuesta a las tensiones que en todo caso crean todas aquellas cosas que en su alteridad se resisten a ese determinado orden o que el mismo orden segrega.

Basta con ver, por ejemplo, cómo se relacionaba la sociedad medieval, fundamentalmente en la Baja Edad Media, con la enfermedad. En principio y para entender la relación con la enfermad es 
necesario mirar la relación con el cuerpo. El cuerpo era fundamentalmente algo desdeñable, despreciable y que debía combatirse. En el cuerpo se configuraba el pecado, de este se servía Satanás para arrebatar al hombre del camino de la salvación, el cuerpo era un obstáculo para la santificación. Veamos cómo refiere el cuerpo, por ejemplo, san Francisco de Asís:

La carne debe ser mortificada y despreciada, tenida por vil y abyecta... odiemos el cuerpo con sus vicios y pecados porque el diablo quiere que vivamos carnalmente... hagamos de nuestros cuerpos objeto de oprobio y desprecio... es el enemigo mediante el cual se cometen pecados (Admoniciones, 10, 2).

En el imaginario más extendido de la época, el hombre era un ser imperfecto, proclive al pecado, cuyo fin último era llegar a la santidad. El deber ser del hombre era alcanzar la salvación y esta se obtenía siguiendo cuidadosamente unos preceptos que estaban en contradicción con las inclinaciones del cuerpo.

Pero aparece una primera dicotomía en relación con el cuerpo, si bien el cuerpo era obstáculo de la salvación, era en cierta forma también el vehículo para lograrla en la medida en que si se lograba domesticarlo mediante la mortificación, someterlo a los principios morales, se estaría más cerca a la santificación.

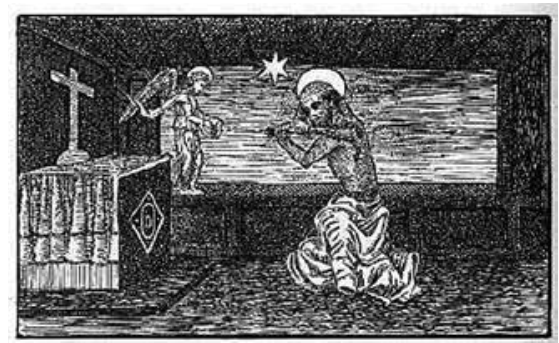

(Santo Domingo rezando. En la cintura lleva el cilicio mientras se flagela).

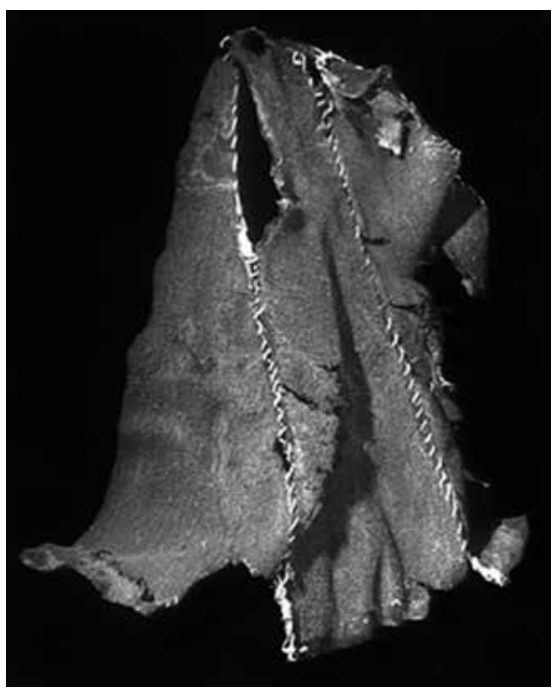

Cilicio de Catalina Cardona, niñera de Juan de Austria (siglo XVI)

De modo que el sufrimiento era en cierta medida necesario. Así pues, la relación con el cuerpo fluctuaba en dos extremos: por un lado el cuerpo visto como obstáculo para la santificación, y por otro, como 
vehículo, pero en ambos casos habría que verlo con desdén o por lo menos con no demasiado apego.

Y ¿qué ocurría entonces con la enfermedad? Otro tanto. La enfermedad fluctuaba también en dos extremos: por un lado era la maldición de Dios al hombre por sus pecados o los de sus padres, y por otro era una prueba divina que había que soportar con paciencia, como ocurrió por ejemplo con Job. Pero en ambos casos, maldición o prueba, el hecho concreto es que Dios se habría separado del enfermo. No olvidemos que Job es abandonado por Dios y dejado a merced de Satanás, quien es el que le inflige todos los males, de modo que en uno u otro caso el enfermo está en estado de maldición. Esta sociedad explica, pues, la enfermedad como una maldición y el enfermo la mayoría de veces es segregado y expulsado del corpus social, confinado en hospitales o simplemente aislado.

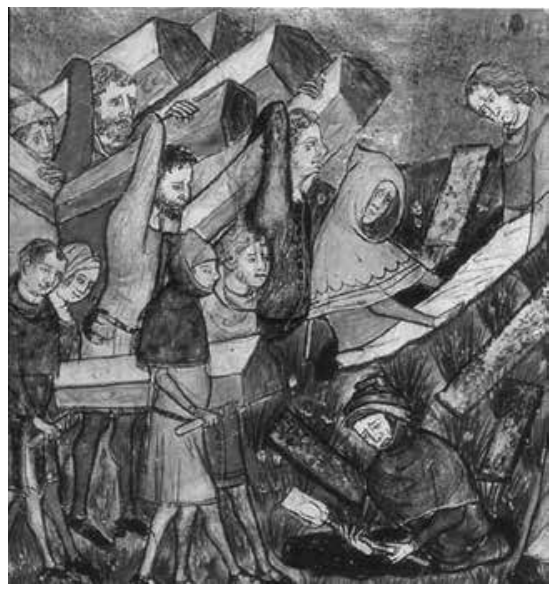

Ilustración sobre el enterramiento de las víctimas de la peste en Tournai, de 1349. Pertenece a un manuscrito titulado: "Anales de Gilles de Muisit" (1272-1353), de Abbot de Saint-Martin. El manuscrito se encuentra en la biblioteca real Alberto I de Bruselas, Bélgica.

Lo que me interesa señalar en este punto es la relación del orden, que para el caso es la salud, con el desorden que representa la enfermedad. Es decir, la relación entre lo normal y lo anormal, para decir que el poder le teme enormemente a aquello que se sale de la norma, a aquello que evade sus categorías por varias razones, pero, sobre todo por una muy poderosa: porque lo anómalo amenaza con arruinar el orden, porque lo interroga, lo cuestiona, lo hace vacilar en sus cimientos y en esa medida atenta contra él. A este respecto Stuart Hall nos dirá:

Las fronteras simbólicas son centrales a toda cultura. Marcar la 
"diferencia" nos conduce, simbólicamente, a cerrar rangos, apoyar la cultura y estigmatizar y expulsar cualquier cosa que se defina como impura, anormal. Sin embargo, paradójicamente, también hace poderosa la "diferencia" y extrañamente atractiva precisamente porque es prohibida, tabú, amenazante para el orden cultural (2010, p. 421).

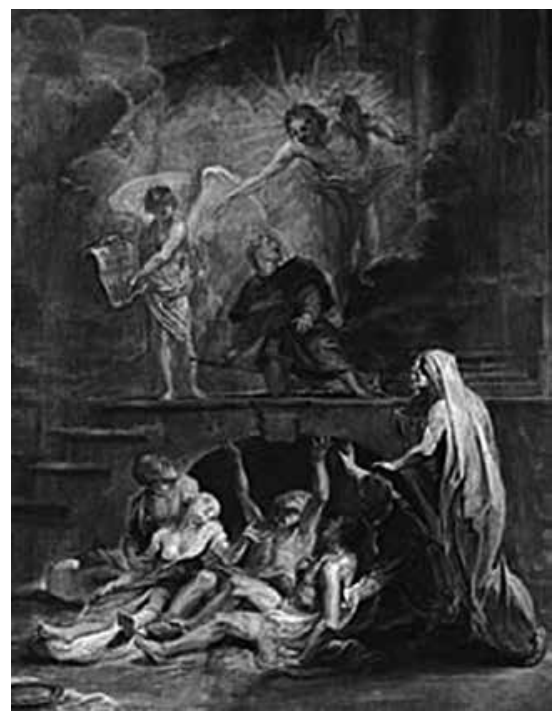

San Roque como patrón de la peste (c. 1623), atribuido a Peter Paul Rubens.

Ahora, habrá que preguntarse: ¿Qué figura representa con mayor elocuencia el temor a la enfermedad que esa que la emparenta con un poder superior, infinito, incuestionable, e implacable, un poder supremo contra el que nada puede el hombre en su insignificancia?

Veamos algunos textos bíblicos del Antiguo Testamento, que fundamentan estas ideas: Levítico, 26, 1-45: “[...] y si os refugiareis a las ciudades muradas, os daré peste [...]"; Deuteronomio, 24, 5-22: "[...] Guárdate bien de incurrir o de merecer la plaga o azote de la lepra [...]"; Deuteronomio, 28, 1-68: "Hará el Señor que se te pegue la peste [...]"; Ezequiel, 14, 19-20: “[...] Y también enviaré Yo pestilencia sobre aquella tierra, y derramaré sobre ella mi indignación causando gran mortandad [...]"; Jeremías, 44, 11-14: "Y castigaré a los judíos que habitan en Egipto, como he castigado a los que habitan en Jerusalén, con la espada, con el hambre y con la peste $[\ldots]$ ".

¿Y qué es la enfermedad sino esa cosa que se resiste al orden, que lo transgrede, que lo violenta, que lo interpela, lo señala y lo cuestiona? Es esa cosa amorfa que crece en forma de tumor, que deforma el cuerpo y lo corrompe. 


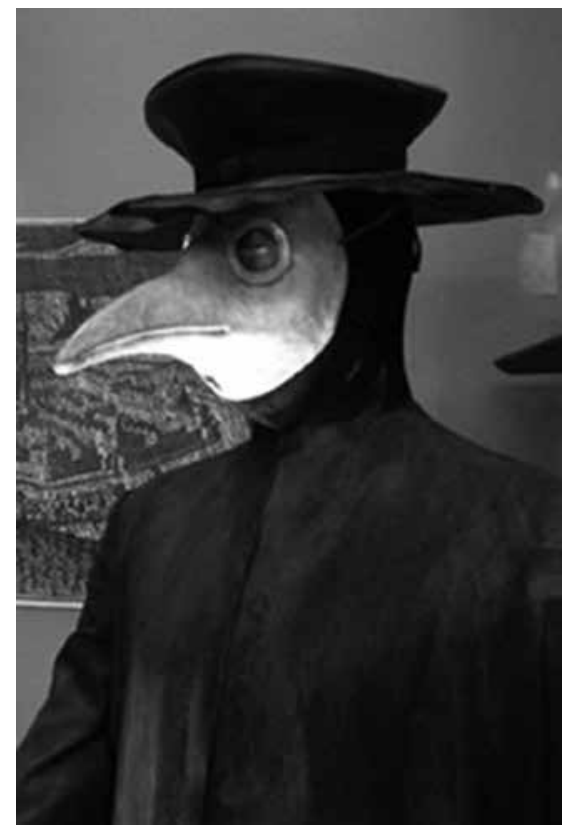

Médico alemán con vestimenta para prevenir el contagio de la peste (siglo XVII). El pico es una máscara de gas primitiva, rellena con sustancias que se pensaba alejaban la peste.

La relación del poder con lo anormal o con lo que, dijéramos, pervierte la norma, suele ser violenta o traducirse en un uso desproporcionado de la fuerza y el orden o estado de cosas se mantendrá hasta que por la fuerza aquello que lo subvierte logre modificar el anterior o instaurar un nuevo orden, cosa que confirmará siempre los temores del poder. Es de este modo como en el curso de la historia los subalternos han logrado hacer parte de la norma.

Pero así como el poder le teme a lo anormal y también le teme al subalterno, los requiere para autoproclamarse, para autodefinirse normal y hegemónico. Aquí conviene ver los dispositivos del poder para su dominación, pues es pertinente observar, como anota Hannah Arendt, que no es posible un sistema de poder totalmente sostenido en la fuerza. Se requiere de la aquiescencia del oprimido para que el poder se sostenga. Por esto la efectividad de los dispositivos de poder dependen de la versatilidad de su implementación, es decir, se extienden e implementan de manera versátil: en el discurso, en los sistemas de producción simbólica, en las imágenes, en los modos de representación, etcétera.

Es a partir de estos dispositivos que el poder se instaura y se mantiene, configurando una especie de deber ser, de statu quo que permea la conciencia de los hombres.

La frigidez de las mujeres en la Edad Media para combatir efectivamente la lujuria, uno de los pecados capitales más obsesivamente señalados en aquella época, no se habría extendido tanto de no ser porque en la conciencia de las mujeres estuviera profundamente grabada su conveniencia. 
Stuard Hall refiere un caso que ejemplifica esto. Se trata de una mujer africana que en 1810 fue llevada a Inglaterra, se la conocía como la Venus africana.

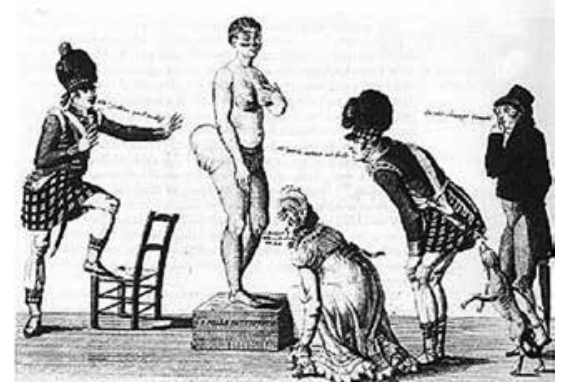

Esta mujer fue utilizada para múltiples fines: se la exhibía como atracción en espectáculos de feria y fue objeto de estudio de naturalistas y etnólogos de la época. La razón, su esteatopigia: acumulación de tejido adiposo en las nalgas.

En otras palabras, era una africana con un enorme trasero y con un alargamiento de sus labios vaginales producto de la manipulación. Esto, que era apreciado y considerado bello entre los hotentotes de donde provenía la mujer, en Inglaterra fue la causa de su exotización. Sara, como la conocían, fue exhibida regularmente durante cinco años en una jaula y atada con cadenas. No obstante, esto era una representación, un espectáculo al que al parecer ella accedía voluntariamente. De hecho, alguna vez acudió a la corte en un juicio para protegerla de la sobreexplotación y se declaró "bajo ninguna restricción" y "feliz de estar en Inglaterra”.

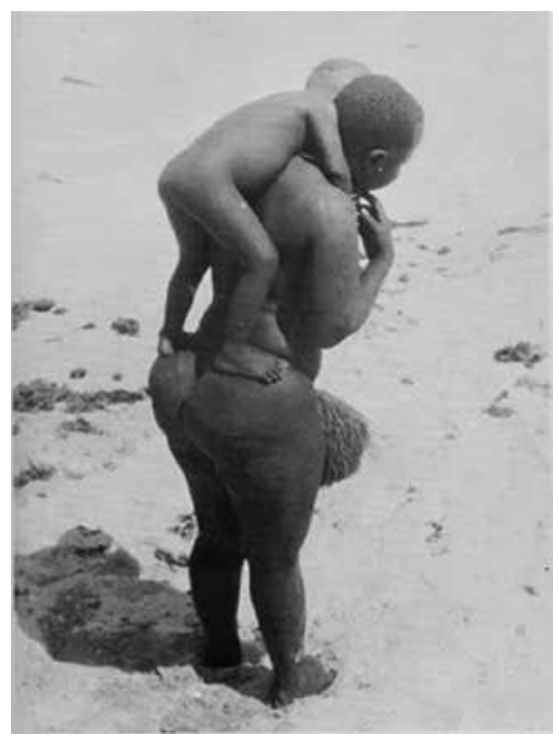

Sara estaba inscrita en ese statu quo a pesar de que, como refiere Hall: "Sara Baartman no existió como "persona". Había sido desensamblada a sus partes relevantes. Fue fetichizada" (p. 436). De modo que ninguna opresión se mantiene por la fuerza pura, dado que depende de un sistema ideológico debidamente instalado incluso en el oprimido. 


\section{El espectáculo y los aparatos de circulación de la ideología}

El hecho de que en la sociedad contemporánea el contacto con la realidad se constituya sobre todo a través de los medios de comunicación nos hace pensar que asistimos cada vez menos a la realidad y más a su espectacularización. El resultado de esta realidad mediada es en gran medida la frivolización de los hechos, convertidos en dispositivos generadores de rating.

Ya desde la aparición de la fotografía, en el momento mismo en que las condiciones técnicas le permitieron llegar a cualquier lugar del planeta, el uso principal de la fotografía fue la reportería gráfica, la fotografía al servicio del periodismo, de la noticia. En palabras de Susan Sontag:

Ser espectador de calamidades que tienen lugar en otro país es la experiencia intrínseca de la modernidad, la ofrenda acumulativa de más de siglo y medio de actividad de esos turistas especializados y profesionales llamados periodistas. Las guerras son ahora también las vistas y sonidos de las salas de estar (2003, p. 7).

Dicha funcionalidad de la fotografía presupone un principio de objetividad, no obstante esa imagen que quiere informar con objetividad indefectiblemente sentará posición, afirmará, juzgará, resignificará o conferirá sentido. En otras palabras, elaborará un relato a partir de un hecho. Por ejemplo, la nota al pie de la foto hace las veces de explicación o de falsificación, según sea el caso. En palabras de Sontag:

Es así como a comienzos de las guerras balcánicas entre serbios y croatas circulaban las mismas fotografías de niños muertos en los bombardeos. Las mismas fotografías servían a unos y a otros para dar cuenta de esos niños como víctimas a manos del enemigo y justificar su guerra. Bastaba, entonces, con cambiar el pie de foto y la falsificación estaba hecha, efectivamente hecha (p. 13).

La imagen se ha convertido en dispositivo hegemónico en términos de producción de información. La Guerra Civil española fue la primera en ser cubierta por fotógrafos, la guerra de Vietnam fue la primera en ser transmitida por televisión, y desde entonces, como dice Sontag, "las batallas y las masacres rodadas al tiempo que se desarrollan han sido componente rutinario del incesante caudal de entretenimiento doméstico de la pequeña pantalla" (p. 14). 
Es así como paulatinamente la ficción se mezcla con la realidad al punto que en ocasiones es difícil establecer la diferencia, una vez la realidad ha sido mediatizada. Los medios de comunicación y todo su andamiaje informativo y especulativo, toda su sobreproducción de imágenes, de registros en tiempo real, la transmisión y retransmisión de los hechos, en su afán de registrar e informar sobre la realidad, tienen la facultad de depredarla, de digerirla y de vaciarla de sentido. Los hechos pasados por los medios dejan de ser y se convierten en simulacros de sí mismos, dando lugar a lo que Jean Baudrillard llamó hiperrealidad:

De ahí la histeria característica de nuestro tiempo: la de la producción y reproducción de lo real. La otra producción, la de valores y mercancías, la de las buenas épocas de la economía política, carece de sentido propio desde hace mucho tiempo. Aquello que toda una sociedad busca al continuar produciendo, y superproduciendo, es resucitar lo real que se le escapa. Por eso, tal producción "material" se convierte hoy en hiperreal. Retiene todos los rasgos y discursos de la producción tradicional, pero no es más que una metáfora. De este modo, los hiperrealistas fijan con un parecido alucinante una realidad de la que se ha esfumado todo el sentido y toda la profundidad $y$ la energía de la representación. Y así, el hiperrealismo de la simulación se traduce por doquier en el alucinante parecido de lo real consigo mismo (1978, p. 49).

Esta indeterminación de límites genera, entre otras cosas: confusión, niveles de incertidumbre y dificultades para dimensionar el valor de los acontecimientos. En general se percibe en estos tiempos, cuando todo acto humano pasa por la espectacularización de los medios, una tendencia a la frivolización de los hechos. Así que la imposibilidad de ver, la ceguera, se extiende e invade todas las retinas, yuxtaponiendo imágenes unas sobre otras y reemplazando la realidad por su simulacro espectacular, o en palabras de Jean Baudrillard:

Esta guerra libera, gracias al poder de los medios de comunicación, una masa exponencial de estupidez, no la estupidez propia de la guerra, ya de por sí considerable, sino de estupidez funcional, profesional, de quienes pontifican en el comentario perpetuo del acontecimiento, de todos los Bouvard y Pécuchet de turno, de los falsos aventureros de la imagen perdida, de los individuos de la $\mathrm{CNN}$, de todos los chantajistas de la estrategia y de la información que nos habrán hecho experimentar como nunca hasta la fecha el vacío de la televisión. Hay que decir que esta guerra constituye un test 
despiadado. Felizmente, nadie va a exigirle cuentas a tal o cual (experto o general, o intelectual de turno) por las tonterías o las sandeces que haya proferido el día antes, puesto que quedarán borradas por las del día siguiente. De este modo, todo el mundo queda amnistiado gracias a la sucesión ultrarrápida de acontecimientos falsos y de discursos falsos. Un lavado de la estupidez mediante la escalada de la estupidez, que restaura una especie de inocencia total, la de los cerebros lavados, limpiados, atontados no por la violencia sino por la siniestra insignificancia de las imágenes (1991, p. 51).

No obstante esta siniestra insignificancia de las imágenes a la que se refiere Baudrillard es responsable en gran medida de la configuración de imaginarios, y contribuye en la conformación de la idea que tenemos del mundo y de nosotros mismos. Pero también es necesario entender que en la edificación de estos imaginarios nos asiste una corresponsabilidad, dado que en la elaboración de sentidos intervienen los dispositivos mediáticos, los que los reciben y consumen y aquellos que hacen la crítica a dichos dispositivos.

De igual manera ocurre con el cine, que partiendo de la ficción intenta reflejar y dar cuenta de una realidad de la que procede. Pero con excesiva frecuencia la explicación que se propone el cine a propósito de, por ejemplo, el conflicto armado en Colombia, suele ser producto de la irreflexión y en esta medida suele parecerse a las ideas generalizadas que se tienen del conflicto. Es en esta circunstancia en la que se impone la necesidad de entender de qué manera se tejen las tramas simbólicas que configuran imaginarios y confieren sentidos a las sociedades.

\section{La violencia en Colombia}

Colombia, durante su historia, ha atravesado varios periodos de violencia que pueden verse en un plano general de la siguiente manera: en primer lugar, las guerras civiles del siglo XIX, que terminarán con la guerra de los Mil Días; en segunda instancia el periodo denominado la Violencia, claramente delimitado entre 1948 y 1953, que tendrá fin con el Frente Nacional, y en última instancia el periodo que algunos estudios denominan tercera Violencia, que es el que se extiende desde el Frente Nacional hasta nuestros días.

Hasta antes de la que aquí denominamos tercera Violencia, la raíz del conflicto colombiano estaba claramente definida: se trataba de dos partidos políticos que dividían 
la nación y que pugnaban por el poder, pero una vez conjurado y establecido el acuerdo de paz entre los partidos, los actores del conflicto cambian, el fenómeno violento muta y se metamorfosea, de suerte que el conflicto armado posterior a la Violencia, es decir al que aún asistimos, se torna mucho más complejo, difícil de significar.

Las guerrillas liberales fueron reemplazadas por otras guerrillas de corriente radicalmente de izquierda: el Ejército de Liberación Nacional (ELN), el Ejército Popular de Liberación (EPL), el Movimiento 19 de Abril (M19). Al tiempo surgen los paramilitares, grupos de extrema derecha en respuesta a las acciones de las crecientes guerrillas. Todo ello en el marco de un vertiginoso cambio en los modelos económicos y las prácticas sociales altamente afectadas por la incursión del narcotráfico, que a su vez permea a la sociedad en todos los sectores y, por supuesto, también a la guerrilla y los paramilitares, estableciendo acuerdos con unos y otros para el control del territorio.

A partir de ahora los actores del conflicto jugarán en varios bandos, conformando alianzas y antagonías aleatorias y coyunturales que devendrán en relaciones arbitrarias a las que será difícil hallar significado.

El resultado de ello no es otro que una violencia cruenta, un gran derramamiento de sangre, desplazamiento forzado y gran inestabilidad social.

En medio de este panorama, la población realiza ingentes esfuerzos para reconstruir el tejido social y pugna por crear un retrato que permita dar cuenta del dolor o por lo menos expresarlo, quizá como una acción de duelo, a propósito de lo cual algunos estudios afirman que el gran problema de la violencia en Colombia es que no ha habido nunca verdadera reparación de las víctimas ni lugar al duelo.

\section{Configuraciones de la violencia en el cine colombiano}

Diecinueve años había vivido como quien sueña: miraba sin ver, oía sin oír, se olvidaba de todo, de casi todo. Al caer, perdió el conocimiento; cuando lo recobró, el presente era casi intolerable de tan rico y tan nítido, también las memorias más antiguas y más triviales [...] No solo le costaba comprender que el símbolo genérico perro abarcara tantos individuos dispares de diversos tamaños y diversa forma; le molestaba que el perro de las 
tres y catorce (visto de perfil) tuviera el mismo nombre que el perro de las tres y cuarto (visto de frente). $\mathrm{Su}$ propia cara en el espejo, sus propias manos, lo sorprendían cada vez [...] Había aprendido sin esfuerzo el inglés, el francés, el portugués, el latín. Sospecho, sin embargo, que no era muy capaz de pensar. Pensar es olvidar diferencias, es generalizar, abstraer. En el abarrotado mundo de Funes no había sino detalles, casi inmediatos.

He apañado aquí extractos del cuento de Jorge Luis Borges Funes el Memorioso, solo con el propósito de metaforizar lo que creo suele ocurrir con el cine colombiano cuando se ocupa de la violencia.

A Funes le ocurre que es incapaz de pensar las cosas, pues su razón se queda anclada en la apariencia de la cosa, en todo lo que de ella llega a sus sentidos. El extremo imposible que plantea Borges en Funes lo desprovee del ser sujeto; Funes no interpreta, su percepción del mundo es literal. De un modo parecido le ocurre a gran parte del cine colombiano, en el que la reproducción de la violencia es literal, pocas veces indaga con hondura en ella o la metaforiza.

Si pensáramos en la violencia como síntoma, apelando a la perspectiva freudiana, según la cual el síntoma es la expresión de tensiones psíquicas, y manteniéndonos en esta relación violencia-síntoma, podríamos pensar la violencia como el síntoma de las tensiones de nuestra sociedad y a gran parte del cine colombiano anclado en ese síntoma, es decir, en la parte más exterior del conflicto, en la manifestación de las tensiones y no en lo que las produce.

Quiero ocuparme ahora de la tensión entre guerrilla, ejército y paramilitares y ver de qué modo el cine colombiano del periodo que nos ocupa ha abordado el tema. Veamos algunas de las películas que se ocuparon del tema entre 1990 y 2008. Incluimos en esta lista algunas películas que si bien no tratan el tema directamente, lo que ocurre en ellas puede interpretarse como consecuencia directa de esta tensión, como ocurre con el desplazamiento forzado y la migración ilegal a Estados Unidos por causa de la violencia que generó la tensión entre los grupos armados:

- Edipo alcalde, Jorge Alí Triana, 1996.

- Golpe de estadio, Sergio Cabrera, 1998.

- El intruso, Guillermo Álvarez, 1999. 
- El séptimo cielo, Juan Fischer, 1999.

- La toma de la embajada, Ciro Durán, 2000.

- La primera noche, Luis Alberto Restrepo, 2003.

- Karmma, el peso de tus actos, Orlando Pardo, 2006.

- Soñar no cuesta nada, Rodrigo Triana, 2006.

- Esto huele mal, Jorge Alí Triana, 2007.

- La milagrosa, Rafael Lara, 2008.

- Los actores del conflicto, Lisandro Duque, 2008.

- Paraíso travel, Simon Brand, 2008.

- PVC-1, Spiros

Stathoulopoulos, 2008.

Estas películas en mayor o menor grado involucran en su relato la violencia producto de la tensión entre los grupos armados. Cada una de ellas presenta hechos que pudieron haber ocurrido o que en realidad ocurrieron, ya que algunas se basaron en hechos reales. No obstante este parentesco con la realidad, pocas de ellas logran alguna hondura en los hechos presentados, la mayoría recrean el hecho violento pero pocas lo reflexionan.
Lo que resulta de esta manera de presentar la violencia es una confirmación de lo que aquíllamamos imaginarios de la violencia, que son en muchas ocasiones explicaciones simplificadoras del hecho violento. Voy a centrarme como ejemplo en tres de las películas mencionadas: Edipo alcalde (1996) y Golpe de estadio (1998).

\section{Edipo alcalde (1996)}

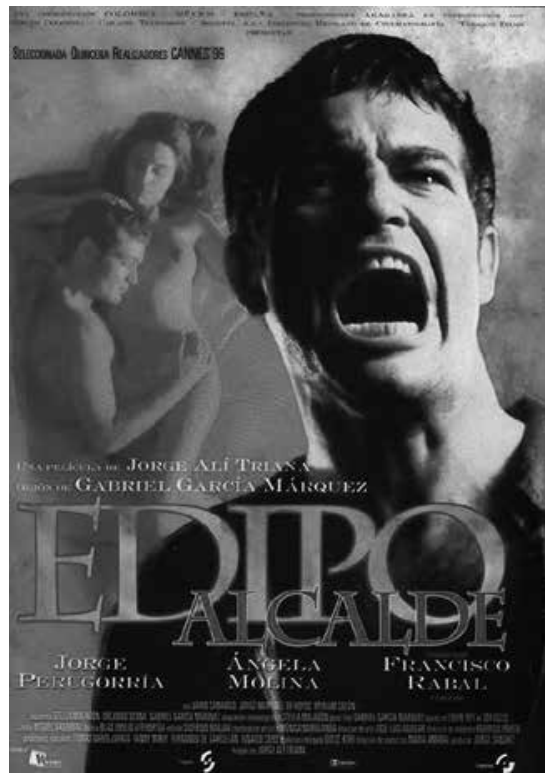

Duración: 99 minutos

Director: Jorge Alí Triana

Guion: Gabriel García Márquez

La película es una transliteración de la obra de Sófocles Edipo rey. Traslada el mito a un espacio y tiempo completamente distintos y distantes y es de ese modo que en una población 
remota de la geografía colombiana cobrarán vida Edipo, Layo, Yocasta, Creonte y Tiresias, en un relato que no logra ser verosímil, pero que en todo caso confirma los imaginarios con los que frecuentemente se explica la violencia en nuestro país.

Edipo Alcalde propone un escenario en el que la guerrilla y los paramilitares pugnan por el control de un pueblo de algún lugar de la cordillera andina colombiana. En el film la figura del Ejército y en general de todo aquello que representa al Estado colombiano y en este sentido la figura preservadora del orden, se presenta marginal e impotente, de suerte que se percibe como una pieza más de ese engranaje del caos que en su marginalidad cómplice preserva una anomalía que tiende a instaurarse como norma.

Este dibujo intenta retratar la circunstancia en la que efectivamente en algunos lugares de Colombia el Estado estaba ausente o su presencia se hallaba modificada o desprovista de sus funciones, de su razón de ser en tanto guardián del orden, la ley y el bienestar de la población.

En algunas circunstancias las fuerzas militares se aliaban a una de las fuerzas en conflicto, generalmente los paramilitares, aunque también se conocen alianzas con la guerrilla pero son mucho menos frecuentes; dicha alianza le adjudicaba libertad de acción al grupo armado ilegal en virtud de intereses de control del territorio mantenido por el terror.

En una circunstancia como esta, la vida diaria de los pobladores se torna compleja, las relaciones filiales son inestables, los códigos de convivencia se enrarecen y modifican de manera coyuntural y arbitraria, lo que origina una gran incertidumbre, inestabilidad y miedo. Son muy frecuentes en estas circunstancias los actos violentos sobre la población civil con fines ejemplarizantes, pero que casi nunca obedecen a reglas claras.

Una gran cantidad de elementos contribuyen a la incertidumbre y dicha incertidumbre es buscada intencionalmente por los grupos en pugna, uno de ellos, quizá el más efectivo, es la indumentaria de los perpetradores de los actos violentos.

Para el caso de las masacres, por ejemplo, el grupo que la ejecuta está siempre provisto de camuflado, indumentaria que usan tanto el Ejército como la guerrilla y los paramilitares, de suerte que a la población le resulta difícil identificarlos. Los testimonios que cito 
a continuación recogidos por la investigadora María Victoria Uribe en su libro Antropología de la inhumanidad (2004), ejemplifican el estado de incertidumbre de los pobladores en zonas de conflicto:

- Mujer joven a la que le mataron la familia: "Ellos llegaron a la casa. Uno no puede decir que esta es la verdad o que no es la verdad. Uno los ve lo mismo, porque uno no sabe ni quién es el uno ni quién es el otro".

- Un campesino se refiere a la confusión, así:

"Todos los uniformes son el mismo. Hoy en día hay una confusión en este país. Hoy en día no solamente el Ejército es el que se viste de prendas como el uniforme. Años atrás solamente el Ejército era el que uno veía que usaba el uniforme de camuflado. Hoy en día no. Todos se visten lo mismo y ahí es donde uno se confunde y no sabe qué hacer. Como campesino, todos los uniformes son el mismo."

En este estado de cosas, en medio de esta ambigüedad que no permite identificar la amenaza ni al enemigo, se establece la lógica de todos contra todos y se instaura el sentido trágico de la historia en el que operan varias percepciones. Dos de ellas consideradas en una investigación realizada por la Corporación
Alotropía, en la que se indaga por los factores que contribuyen a la vinculación de niños a los grupos armados en Colombia:

Una, según la cual las víctimas se ven no como víctimas de una situación de injusticia, de anomalía en el funcionamiento de la ley en un Estado social de derecho, sino como corresponsables de su tragedia en la medida en que las víctimas no se protegieron a sí mismas o de alguna manera buscaron su suerte.

Otra, según la cual la guerra es una condición natural e inevitable en la que hay que aprender a sobrevivir, y el aprendizaje consiste en subsistir en un mundo en el que las alianzas son inestables, las reglas arbitrarias y los códigos cambiantes, situación que alimenta la sensación de caos, desconfianza, indefensión e impotencia.

Estas percepciones no permiten establecer responsabilidades en la generación de violencia como tampoco explican las complejidades que la producen. Perspectivas como estas son muy comunes en la población en general y en las víctimas en particular y son justamente las que le confieren a la violencia un carácter de ininteligibilidad e impiden pensarla, tal como las posturas 
que señalaba Walter Benjamin y que definen la violencia como inherente al ser humano y a todas las especies sobre la tierra. Si la violencia es inherente al hombre y a su historia ya no habría que pensarla, habría entonces que aceptarla y vivir con ella.

Esta postura que procede del sentido trágico de la historia y que plantea la violencia también desde la inevitabilidad y la incomprensión, como un sino que está por encima de la voluntad de los hombres pero que gobierna sus destinos, el mismo que padecía el hombre griego y por el que explicaba lo inexplicable de su existencia, es el que reproduce la película Edipo alcalde con la transliteración del mito griego a la circunstancia colombiana, convirtiendo el conflicto en el sino trágico, imposible de comprender y el que habría que aceptar en tanto inevitable.

\section{Golpe de estadio (1998)}

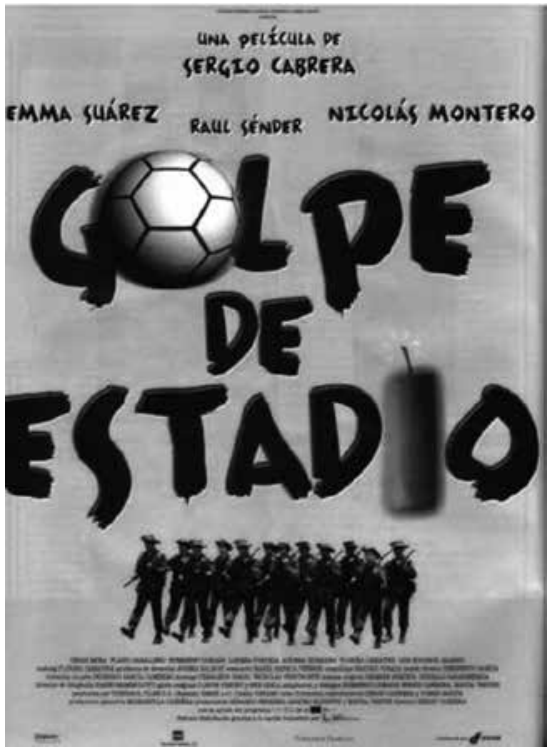

Duración: 120 minutos

Dirección: Sergio Cabrera.

Guion: Claude Pimont y Ben Odell

La película pone en conjunción dos elementos relevantes del imaginario social colombiano: el fútbol y el conflicto armado, planteando este último como elemento distensor. Es una película que pretende abordar el conflicto desde el humor, plantea que el conflicto es fácilmente superable y que algo como el fútbol serviría como escenario de reconciliación, de suerte que el conflicto podría arreglarse de manera amistosa. Algo así como decir: “¿Para qué pelear, por qué no mejor arreglar por las buenas?".

En varias ocasiones el Gobierno ha iniciado procesos de paz 
configurados en mesas de negociación y procesos de diálogo con los grupos alzados en armas, y campañas presidenciales han logrado vencer en la contienda política bajo la promesa de la paz. Por supuesto, los procesos de negociación suelen ser más complejos de lo que la población tiende a considerar y generalmente fracasan porque han nacido muertos. No obstante, tanto en campaña como en el ejercicio de las facultades presidenciales, los presidentes suelen hacer un gran despliegue mediático en torno al tema de la paz.

Durante el periodo presidencial de Belisario Betancur, por ejemplo (1982-1986), todos los medios de comunicación invitaban a cada colombiano a pintar y a portar una paloma de la paz. Se convocó incluso a una marcha en la que muchas personas salieron a las calles con una paloma pintada en la cara.

Como ya se ha dicho, en ese entonces las conversaciones se habían iniciado con la Unión Patriótica (UP) y el M19. En medio del fragor publicitario se decía que por vía del diálogo se lograría la paz, cuando quienes negociaban sabían que el asunto era mucho más complejo, que había muchos intereses en juego y que grandes fuerzas se oponían a la consolidación de aquella paz: el narcotráfico, los paramilitares y algunas élites terratenientes que, como ya se advirtió, no tenían interés en un cambio del estado de cosas en el que ellos tenían el control de algunos territorios y para quienes la eventual participación de los grupos enemigos en el poder podría implicar gran peligro para sus intereses.

Sin embargo, y resultado del despliegue publicitario, se extendía la idea de que la paz estaba cerca, y coloquialmente, de que hablando se arreglarían las cosas. Esta visión simplista del conflicto, de la guerra y de la paz, estaba extendi$\mathrm{da}$, era frecuente escuchar en la calle a personas diciendo cosas como: “Qué hacemos peleando, si finalmente todos somos colombianos?". $\mathrm{Y}$ es justamente lo que confirma la película Golpe de estadio, al considerar ingenuamente que los actores en conflicto se enfrentan por razones ideológicas, desconociendo las razones económicas y de control de territorio que promueven la guerra, así como la participación del narcotráfico en este escenario bélico. En definitiva, la película plantea el conflicto en Colombia como dos fuerzas que están en conflicto por una 
suerte de malentendido que puede resolverse dialogando.

\section{Reflexiones sobre el cine}

Por último quiero aprovechar esta ocasión para proponer un cine urgente, entendiendo urgente a lo que surge de la necesidad. Con frecuencia he escuchado decir a los cinematografistas que ellos hacen cine para la gente, que su cine es popular y sin pretensiones, lo cual lo localiza inmediatamente en lo que Barthes llamó el habla mítica, esa impostura que simula, que imposta comunión con lo cotidiano con el propósito de persuadir a la mayoría, a lo que suele llamarse el gran público. Yo considero en cambio que hace falta un cine, por lo menos en Colombia, que se oponga al lugar común, un cine que se erija como un acto de creación.

A manera de invitación, los dejo con las palabras que pronunció Gilles Deleuze durante una conferencia en la cátedra de los martes de la Fundación Femis, queriendo responder a la pregunta “¿Qué es un acto de creación?":

Casi todo el mundo sabe bien que tener una idea es un acontecimiento raro, que ocurre raramente, que tener una idea es una especie de fiesta.
Un creador no es un ser que trabaja por el placer. Un creador no hace más que aquello de lo que tiene absolutamente necesidad.

El arte es la única cosa que resiste a la muerte.

¿Qué es tener una idea cinematográfica? Resistencia. Acto de resistencia. Desde Moisés, hasta el último Kafka, hasta Bach. Recuerden que la música de Bach es su acto de resistencia. ¿Contra qué? No es el acto de resistencia abstracto, es acto de resistencia y de lucha activa contra la repartición de lo sagrado y lo profano. $Y$ este acto de resistencia en la música culmina con un grito. Como también hay un grito en Woyzek, hay un grito en Bach: "iAfuera, afuera, no quiero verlos!". Eso es el acto de resistencia. A partir de esto el acto de resistencia tiene dos caras: es humano y es también acto de arte.

Solo el acto de resistencia resiste a la muerte, sea bajo la forma de obra de arte, sea bajo la forma de una lucha de los hombres.

$\mathrm{Y}$ ¿qué relación hay entre la lucha de los hombres y la obra de arte?

La relación más estrecha y para mí la más misteriosa.

Exactamente eso que quería decir Paul Klee cuando decía: "Ustedes saben, falta el pueblo". El pueblo falta y al mismo tiempo no falta. El pueblo falta, esto quiere decir que esta afinidad fundamental entre la obra de arte y un pueblo que todavía no existe, no es ni será clara jamás. No hay obra de arte que no haga un llamado a un pueblo que no existe todavía. 


\section{Referencias}

Álvarez, C. (1989). Sobre cine colombiano y latinoamericano. Bogotá: Universidad.

Álvarez, L. (1989). Historia del cine colombiano. Nueva historia de Colombia (vol. VI). Bogotá: Planeta Colombiana Editorial.

Aristóteles. La gran moral. Recuperado de: http://www.filosofia.org/ cla/ari/azc02087.htm

Benjamin, W. Para una crítica de la violencia. Escuela de Filosofía Universidad ARCIS. Recuperado de. http://www.philosophia.cl/biblioteca/Benjamin/violencia.pdf

Benjamin, W. (1991). Para una crítica de la violencia y otros ensayos. En Iluminaciones IV. Madrid: Taurus.

Benjamin, W. (1971). Tesis de filosofía de la historia. En Angelus novus. Barcelona: Edhasa.

Baudrillard, J. (1978). Cultura y simulacro. Barcelona: Kairós.

Baudrillard, J. (1991). La guerra del Golfo no ha tenido lugar. Barcelona: Anagrama.

Baudrillard, J. (2005). La violencia del mundo. Buenos Aires: Libros del Zorzal.
Castoriadis, C. (1988). Los dominios del hombre. Las encrucijadas del laberinto. Barcelona: Gedisa.

Castoriadis, C. (1990). El mundo fragmentado. Buenos Aires: Altamira.

Cornblit, O. (2002). Violencia social, genocidio y terrorismo. México: Fondo de Cultura Económica.

Díaz del Castillo, B. (1939). Haciendo referencia a Francisco López de Gómara en la narración de la batalla de Centla en Historia verdadera de la conquista de la Nueva España. Gumucio Dagrón, A. (1979). Colombia, la censura feudal. En Cine, censura y exilio en América Latina. La Paz: Film.

Foucault, M. (1968). Las palabras y las cosas, una arqueología de las ciencias humanas. Buenos Aires: Siglo XXI.

Hall, S. (2010). Sin garantías: trayectorias y problemáticas en estudios culturales. Bogotá: Instituto de Estudios Sociales y Culturales Pensar/Universidad Javeriana/Instituto de Estudios Peruanos/Universidad Andina Simón Bolívar. Bogotá: Envión Editores. 
Jaramillo Morales, A. (2006). Nación y melancolía: narrativas de la violencia en Colombia (1995-2005). Bogotá: Alcaldía Mayor de Bogotá. Laurens, M. (1988). El vaivén de las películas colombianas (de 1977 a 1987). Bogotá: Contraloría General de la República.

Laurens, M. (1988). El vaivén de las películas colombianas (de 1977 a 1987). Bogotá: Contraloría General de la República.

Martínez Pardo, H. (1978). Historia del cine colombiano. Bogotá: Editorial América Latina.

Ocampo López, J. y Ocampo T., J. F. (2008). Historia de las ideas políticas en Colombia (pról. Hoyos Vásquez, G.). Bogotá: Taurus.

Schumann, P. (1987). Historia del cine latinoamericano. Buenos Aires: Legasa.

Salcedo Silva, H. (1981). Crónicas del cine colombiano 1897-1950. Bogotá: Carlos Valencia Editores.

Sánchez G., G. (1991). Guerra y política en la sociedad colombiana. Bogotá: El Áncora Editores.
Sánchez Méndez, I. (comp.). (1987). Cine de la violencia. Bogotá: Universidad Nacional de Colombia. Compilación de guiones colombianos (realizados y no realizados), que giran en torno al tema de la violencia política.

Sontag, S. (2003). Ante el dolor de los demás. Bogotá: Alfaguara.

Suárez Melo, M. (1984). Legislación cinematográfica colombiana. Bogotá: Suárez Melo. Útil recopilación de las diversas legislaciones colombianas en el campo del cine.

Uribe Alarcón, M. (2004). Antropología de la inhumanidad, un ensayo interpretativo sobre el terror en Colombia. Bogotá: Norma.

VV. AA. (2006). Historia de Colombia, todo lo que hay que saber. Bogotá: Taurus.

VV. AA. (2005). Largometrajes colombianos en cine y video. Bogotá: Fundación Patrimonio Fílmico Colombiano.

Valverde, U. (1978). Reportaje crítico al cine colombiano. Cali: Toronuevo. 